\title{
The Functionally Refractory Patient in Diabetes- Prevalence and Predictors within Specialist Care Registries
}

\author{
Ronnie Aronson, MD, FRCPC, FACE
}

Executive Director, LMC Diabetes \& Endocrinology, Toronto, Canada

\begin{abstract}
A recent literature survey reviewed all published global registries, evaluating them for patient outcome data and characteristics. Using registry data to define the patient characteristics of refractory patients, the authors characterized the functionally refractory patient in diabetes and provided a predictive model to facilitate the recognition of such a patient in a specialist practice. At the specialist level, the authors have identified common predictive elements of a functional refractory status: insulin usage, greater number of microvascular complications, earlier age of onset and longer durations of diabetes, and greater complexity and number of therapies. This editorial provides a brief overview and commentary of the authors' original descriptive literature review and findings.
\end{abstract}

\section{Keywords}

Database, diabetes, refractory, registry, specialist

Disclosure: Ronnie Aronson, MD, FRCPC, FACE, has received speaker and consulting fees from AstraZeneca, Becton Dickinson, Boehringer Ingelheim, Bristol-Myers Squibb, Eli Lilly, Janssen, Medtronic, Novo Nordisk, Sanofi, and Takeda.

Open Access: This article is published under the Creative Commons Attribution Noncommercial License, which permits any noncommercial use, distribution, adaptation, and reproduction provided the original author(s) and source are given appropriate credit.

Received: February 25, 2015 Accepted: April 10, 2015 Citation: US Endocrinology, 2015;11(1):30-1 DOl: http://doi.org/10.17925/USE.2015.11.1.30

Correspondence: Ronnie Aronson, MD, FRCPC, FACE, Executive Director, LMC Diabetes \& Endocrinology, Toronto, Canada. E: Ronnie.Aronson@Imc.ca

Support: Editorial assistance was provided by Katrina Mountfort, PhD, from Touch Medical Media, London, UK, funded by Touch Medial Media.

Patient registries are essential in the management of diabetes. ${ }^{1,2}$ Numerous diabetes registries have been implemented ${ }^{3-5}$ in primary care populations, supporting the assessments of patient health, care delivery practices, primary prevention measures, and quality assessment. Patient registries may also be beneficial to specialist healthcare providers (HCPS) that primarily support referred patients who have longer treatment histories, more advanced diabetes, and more severe diabetic complications. ${ }^{6}$ In particular, registries may help in developing more effective strategies to manage patients and/or populations who are unable to achieve optimal diabetes control despite appropriately prescribed interventions, even when implemented within a specialist care setting. These "resistant" patients may respond to aggressive glycemic control measures with increased mortality versus other diabetic patients. ${ }^{7}$ Such patients have been termed "functionally refractory." In Canada ${ }^{8}$ and in the US, ${ }^{9}$ only $~ 50$ $\%$ of patients having type 2 diabetes successfully reach optimal glycemic targets. Of even greater concern are the patients recognized to be in poor control (glycated hemoglobin $\left[\mathrm{HbA}_{1 \mathrm{c}}\right]>9.0 \%[75 \mathrm{mmol} / \mathrm{mol}]$ ), with estimates ranging from $10-12 \%, 8$ of the general North American diabetes population, and as high as $30 \%$ in managed care organizations. ${ }^{10}$

Recently, Aronson et al. published the findings of a comprehensive literature survey ${ }^{11}$ undertaken between November 2013 and February 2014 that reviewed all published registries of diabetes populations, evaluating them for patient characteristics and outcome data. Their analysis focused on specialist-led patient populations within the reported registries, specifically seeking data for patients who failed to respond to specialist care ("functionally refractory" patients). Univariate logistic regression was used to evaluate baseline patient factors, including demographics, medication use, and medical history, for their ability to predict poor glycemic control (defined as $\mathrm{HbA}_{1 \mathrm{c}}>9.0$ ). Factors found to be significant were then included in a multivariate logistic regression model.

The literature search identified 13 diabetes registries whose databases recorded outcomes of specialist care. The size of the databases included ranged from approximately 200 to more than 220,000. In addition, the Canadian LMC Diabetes \& Endocrinology Registry database $(n=58,280)$ was used to characterize patients having type 2 diabetes, seen in a defined 14-month period. Refractory patients were defined as $\mathrm{HbA}_{1 \mathrm{c}} \geq 9.0 \%$, $(75 \mathrm{mmol} / \mathrm{mol}$ ) despite specialist care for $\geq 1$ year. The primary care registry populations generally showed lower $\mathrm{HbA}_{1 \mathrm{c}}$ ranges $(6.8-7.1 \%$, 51-54 mmol/ $\mathrm{mol})$ than specialist care registries $(7.7-8.6 \%, 61-71 \mathrm{mmol} / \mathrm{mol})$. Registries that further defined "poor control" typically used the threshold of $\mathrm{HbA}_{1 \mathrm{c}}$ $\geq 8.0 \%$ (64 mmol/mol). Higher proportions of "poor control" in patients were reported in specialist care populations. In addition to specialist care itself, several additional baseline characteristics were frequently associated with poor control: duration of diabetes and presence of microvascular complications, as well as the number and complexity of therapies (combinations of insulin and oral anti-diabetic agents [OADs]). 
Within the LMC Diabetes \& Endocrinology Registry, the authors found 10,590 individuals who met the inclusion criteria. Approximately $16 \%$ of the LMC population (1,681 patients) showed $\mathrm{HbA}_{1 \mathrm{c}}>9.0 \%$, meeting the definition of functionally refractory. The single most closely associated factor in predicting a functionally refractory status was insulin use: insulin-treated patients were 3.2 times more likely to be refractory. The refractory subgroup also showed younger age at diagnosis, longer duration of diabetes, higher body mass index (BMI), higher rates of microvascular complications, and more multiple diabetes therapies. This cohort also showed higher blood pressure (BP) and lipid parameters (total cholesterol and triglycerides). Poor glycemia itself may have accelerated the development of complications, but regardless, the empiric observation of complications indicates a higher likelihood of a refractory status developing. The duration of specialist care at LMC was not correlated with refractory status. Patient characteristics not related to outcomes included BMI, waist circumference, ethnicity, and socioeconomic factors.

The few specialist care published registries identified in this study ${ }^{11}$ indicate that this level of care is associated with a greater proportion of patients who persistently remain in poor control. Furthermore, analysis of the LMC Diabetes \& Endocrinology Registry, which contains patients referred for tertiary care for diabetes or associated complications, found that $16.1 \%$ were in persistent poor control $\left(\mathrm{HbA}_{1 \mathrm{c}} \geq 9.0 \%\right.$; $75 \mathrm{mmol} /$ mol). These patients had been part of the clinic, with access to all of its resources, for at least a year, and had remained refractory to usual care measures. The authors suggest that these patients do not have classic therapeutic unresponsiveness; rather, their lack of response represents a functional refractoriness. The proportion of such patients in the LMC Diabetes \& Endocrinology Registry is similar to the rates reported in an earlier analysis of specialist care populations in a Canadian province ${ }^{6}$ and at a diabetes care consortium in Singapore. ${ }^{12}$

This registry analysis ${ }^{11}$ represents a significant attempt to understand the challenges faced by the functionally refractory patient. These patients are at higher risk of microvascular disease ${ }^{13}$ and cardiovascular mortality, which may paradoxically worsen with more aggressive therapy.? Because current guidelines ${ }^{14}$ advocate selecting individual glycemic targets to mitigate this potential risk, recognizing these vulnerable individuals will allow more appropriate strategies to be implemented earlier in their care. The study's strengths include the inclusion of the large LMC Diabetes \& Endocrinology Registry and its representation of patients from multiple regions, ethnicities, and socioeconomic classes, all within the public health system, which controls for typical barriers such as healthcare access and cost and cultural/language barriers. Limitations include the absence of data on compliance, hypoglycemia, and family income.

Feedback on outcomes is a critical step in assessing healthcare delivery practices and in holding teams and team members accountable. Analysis of this large specialist care registry ${ }^{8}$ has confirmed that specialist practices harbor a proportion of functionally refractory patients that may be as high as one of every six patients in active care. Several associated features can be recognized early in their care, helping predict potential outcome. Studies are now needed to better identify the barriers these patients face and to develop more innovative approaches to overcome these barriers.
1. Clement M, Harvey B, Rabi DM, et al., Organization of diabetes care, Can J Diabetes, 2013;37(Suppl. 1):S20-6.

2. MCMahon GT, Dluhy RG, Diabetes report card: time for a winning streak, N Eng/ I Med, 2013;368:1650-1.

3. McAlister FA, Majumdar SR, Eurich DT, Johnson JA, The effect of specialist care within the first year on subsequent outcomes in 24,232 adults with new-onset diabetes mellitus: populationbased cohort study, Qual Saf Health Care, 2007:16:6-11.

Borgermans L, Goderis $\mathrm{G}$, Van Den Broeke C, et al. Interdisciplinary diabetes care teams operating on the interface between primary and specialty care are associated with improved outcomes of care: findings from the Leuven Diabete Project, BMC Health Serv Res, 2009;9:179.

5. Thomsen RW, Friborg S, Nielsen JS, et al., The Danish Centre for Strategic Research in Type 2 Diabetes (DD2), Clin Epidemiol, 2012:4(Suppl. 1):15-9.
6. Shah BR, Hux JE, Laupacis A, et al., Diabetic patients with prior specialist care have better glycemic control than those with prior primary care, J Eval Clin Practice, 2005;6:568-75.

7. Riddle MC, Ambrosius WT, Brillon DJ, et al., Action to control cardiovascular risk in diabetes I: epidemiologic relationships between $\mathrm{A} 1 \mathrm{C}$ and all-cause mortality during a median 3.4-year follow-up of glycemic treatment in the ACCORD trial, Diabetes Care, 2010:33:983-90

8. Leiter LA, Berard L, Bowering CK, et al., Type 2 diabetes mellitus management in Canada: is it improving? Can J Diabetes, 2013:37:82-9.

9. Ali MK, Bullard KM, Saaddine JB, et al., Achievement of goals in U.S. diabetes care, 1999-2010, N Eng/ J Med, 2013;368:1613-24.

10 National Committee for Quality Assurance, 2014 state of health care quality Available at: www.ncqa.org/ReportCards/ HealthPlans/StateofHealthCareQuality/2014TableofContents/
Diabetescare aspx (accessed April 20, 2015).

11. Aronson R, Orzech N, Ye C, et al., Specialist-led registries and predictors of poor glycemic control in type 2 diabetes: insights into the functionally refractory patient from the LMC Diabetes Registry database, I Diabetes, 2015; [Epub ahead of print].

12. Heng BH, Sun Y Cheah JTS, et al. The Singapore Nationa Healthcare Group Diabetes Registry: descriptive epidemiology of type 2 diabetes mellitus, Ann Acad Med Singapore of type 2 diabe

13. Stratton IM, Adler Al, Neil HA, et al., Association of glycaemia with macrovascular and microvascular complications of type 2 diabetes (UKPDS 35): prospective observational study, BMJ 2000;321:405-12.

14. American Diabetes Association, Standards of medical care in diabetes 2013, Diabetes Care, 2013:36(Suppl. 1):S11-66. 